\title{
ÁREA DE PRESERVAÇÃO PERMANENTE DE UM RIO E ANÁLISE DA LEGISLAÇÃO DE PROTEÇÃO DA VEGETAÇÃO NATIVA
}

\author{
PERMANENT PRESERVATION AREA OF A RIVER AND ANALYSIS OF PROTECTION \\ LEGISLATION OF NATIVE VEGETATION
}

\author{
Karla Campagnolo ${ }^{1}$ Geraldo Lopes da Silveira ${ }^{2}$ Alessandro Carvalho Miola ${ }^{3}$ \\ Regis Leandro Lopes da Silva ${ }^{4}$
}

\begin{abstract}
RESUMO
O Novo Código Florestal Brasileiro (NCF), que revoga a Lei n. 4.771/1965, antigo Código Florestal (ACF), regulamenta a definição de Áreas de Preservação Permanente (APPs) das faixas marginais dos cursos d'água, sendo que atualmente sua delimitação deve ser feita a partir da borda da calha do leito regular (LR), diferentemente do ACF, que indicava o início da faixa de APP a partir do leito maior hidrológico (LMH) do rio. Objetivou-se comparar a aplicação no NCF em faixa ciliar de rio, frente ao antigo Código, bem como a diferença entre os mesmos, em uma bacia tipicamente rural. Utilizou-se como estudo de caso o Arroio Grande, definindo-se a extensão do LR, do LMH e respectiva faixa de APP, formando assim, a Faixa de Proteção Permanente (FPP). Dentro de cada faixa de proteção, foi realizada a análise do uso do solo e as dificuldades mais comuns encontradas para delimitação do leito definidor da APP. Por meio dos mapas obtidos, a APP do Arroio Grande deve ser de 50 metros a partir da calha do LR, que se trata da calha delimitada do rio, incluídas as praias e ilhas fluviais. O NCF traz como contribuição permitir aos proprietários a adequação das áreas degradadas com uma faixa menor de preservação e facilitar a definição do LR por meio de imagens de satélite. Assim, podem-se comparar as legislações através dos mapas e concluir que o NCF trouxe alguns avanços, como a facilidade na demarcação da APP, mas é mais brando em relação ao tamanho de área protegida.
\end{abstract}

Palavras-chave: leito de rio; Área de Preservação Permanente; legislação ambiental.

\section{ABSTRACT}

The new Forest Code (NCF) which substitutes the Law No. 4.771, Old Forestry Code (ACF), regulates the definition of Permanent Preservation Areas (APP's) of waterway marginal ranges, considering that currently their delimitation must be done from the edge of the regular bed rail (LR), differently from the ACF, which indicated the APP range beginning from the larger hydrological river bed (LMH). The objective was to compare the application of the NCF in river ciliary range, opposite to the Old Code, as well as the difference between themselves, in a typically rural basin. The Arroio Grande study case was used, the extent of the LR was defined, as well as of LMH and its respective APP range, thus, forming the Permanent Protection Range (FPP). Within each protection strip, it was utilized the land use analysis and also its commonest difficulties that define the boundaries of the APP defining bed. Through the maps which were obtained, the APP of the Arroio Grande must be 50m from the LR rail, which is bounded through this river, and includes river shores

1 Engenheira Florestal, MSc., Rua Domingos Crescêncio, 687/AP 402, CEP 90650-090, Porto Alegre (RS), Brasil. kbcampagnolo@gmail.com

2 Engenheiro Civil, Dr., Professor do Departamento de Engenharia Sanitária e Ambiental, Centro de Tecnologia, Universidade Federal de Santa Maria, Av. Roraima, 1000, CEP 97105-900, Santa Maria (RS), Brasil. geraldo. ufsm@gmail.com

3 Engenheiro Florestal, Dr., Professor do Colégio Politécnico, Universidade Federal de Santa Maria, Av. Roraima, 1000, CEP 97105-900, Santa Maria (RS), Brasil. engenheiroacm@gmail.com

4 Engenheiro Ambiental, MSc., CPRM - Serviço Geológico do Brasil, Av. Doutor Freitas, 3645, CEP 66095-110, Belém (PA), Brasil. regisllsilva@gmail.com 
and islands. The NCF brings as a contribution to permit the owners the adequacy of degraded areas using a minor range of preservation and facilitating the definition of LR by satellite images. Thus, one can compare the laws through the maps and conclude that the NCF has brought some progress such as the ease of in the demarcation of APP, but it is milder compared to the size of the protected area.

Keywords: riverbed; Permanent Preservation Area; environmental legislation.

\section{INTRODUÇÃO}

Problemas como a poluição do ar, água e solo, alterações climáticas e extinção de espécies são conhecidos e nortearam um pensamento comum pela conservação ambiental, cujas leis ambientais têm a função de regular as ações humanas impactantes, não só nas áreas rurais, mas também nas zonas urbanas, nas quais a concentração populacional é maior. Dentro deste cenário de adequação às normas ambientais, sabe-se que muitos produtores rurais não estão regulares em relação à legislação atual, muitas vezes em função da falta de uma perfeita interpretação da lei. Neste âmbito, está inserido o Novo Código Florestal (NCF), publicado em 25 de maio de 2012 e aprovado como Lei n. 12.651, posteriormente modificado pela Lei n. 12.727, ambas revogando a Lei n. 4.771 de 15 de setembro de 1965, o Antigo Código Florestal (ACF).

O Código Florestal Brasileiro, em todas suas versões, tem como essência a manutenção da qualidade de vida de toda a sociedade brasileira, pois entende que a conservação dos ecossistemas e a proteção dos recursos naturais são de interesse comum. Neste contexto, o NCF manteve no seu texto um item muito importante da lei antiga, que é o termo "Área de Preservação Permanente" (APP), declarando que uma APP trata-se de: "área protegida, coberta ou não por vegetação nativa, com a função ambiental de preservar os recursos hídricos, a paisagem, a estabilidade geológica e a biodiversidade, facilitar o fluxo gênico de fauna e flora, proteger o solo e assegurar o bem-estar das populações humanas" (BRASIL, 1965). As APPs de rio têm como função principal a proteção dos recursos hídricos. Entre diversos benefícios, a vegetação ciliar trata-se de uma zona fundamental para a preservação da qualidade da água, conforme destaca Coelho, Buffon e Guerra (2011).

Gonçalves et al. (2012) explicam ainda que o estabelecimento de uma conexão natural destas áreas de APP proporciona a formação de corredores ecológicos, que constituem um meio eficiente de minimizar os prejuízos causados pela fragmentação do habitat para fauna e flora. Criado (2008) diz que há uma necessidade de se evitar a fragmentação da paisagem para a manutenção do fluxo gênico entre espécies.

O NCF declara que a largura da APP de um curso d'água deve ser medida a partir da borda da calha do leito regular (LR), e terá a sua extensão definida pelo tamanho da propriedade, ou seja, propriedades menores podem delimitar uma faixa menor de proteção ao longo do curso d'água. O LR consiste na calha pela qual correm regularmente as águas de um curso d'água durante o ano, sendo este o nível de sua normalidade (TEREZAN, 2005). Apesar disso, o texto da nova legislação continua, assim como no ACF, sem descrever as características que deveriam ser observadas in loco para tal definição.

$\mathrm{Na}$ tentativa de facilitar a aplicabilidade do NCF, o Governo Federal fornece imagens do satélite RapidEye, em alta resolução (5 metros), que são utilizadas como base de informação para o Cadastro Ambiental Rural (CAR), obrigatório a todas as propriedades rurais e serve também para a identificação das APPs.

Diante do exposto, objetivou-se comparar a aplicação da nova lei de delimitação de APPs em faixa ciliar de rio, no âmbito do Código Florestal Brasileiro, frente ao antigo Código, em relação a sua extensão, em uma bacia hidrográfica rural em Arroio Grande, distrito de Santa Maria - RS. Através dos cenários obtidos, analisou-se a funcionalidade da faixa marginal de rio frente aos seus objetivos de conservação. Também foram discutidas as dificuldades encontradas e indicadas alternativas para solução de impasses. 


\section{MATERIAL E MÉTODOS}

\section{Caracterização da área de estudo}

A bacia hidrográfica do Arroio Grande possui área total de $299 \mathrm{~km}^{2}$ (Figura 1) e fica inserida na Região Hidrográfica do Guaíba. Possui feições de encosta à montante e de planície à jusante, abrangendo o território dos municípios de Itaara, Santa Maria, Júlio de Castilhos e Silveira Martins, região central do RS.

O trecho do curso d'água em estudo faz parte do canal principal do Arroio Grande e situa-se entre as coordenadas de montante $29^{\circ} 35^{\prime} 52,96^{\prime}$ 'S e $53^{\circ} 42^{\prime} 50,04^{\prime}$ 'O, ponto de confluência dos arroios Taboão e

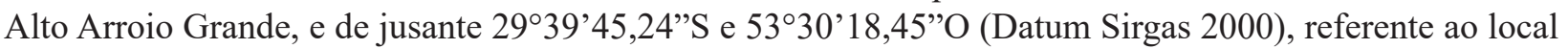
de desvio, onde o Arroio Grande se liga ao Arroio do Meio. O trecho analisado possui 10,6 km, e está localizado a 140 metros de altitude, sendo que o ponto final está a 81 metros de altitude acima do nível do mar, segundo os dados do satélite GeoEye-1, o que representa uma variação de quase 60 metros de altitude.
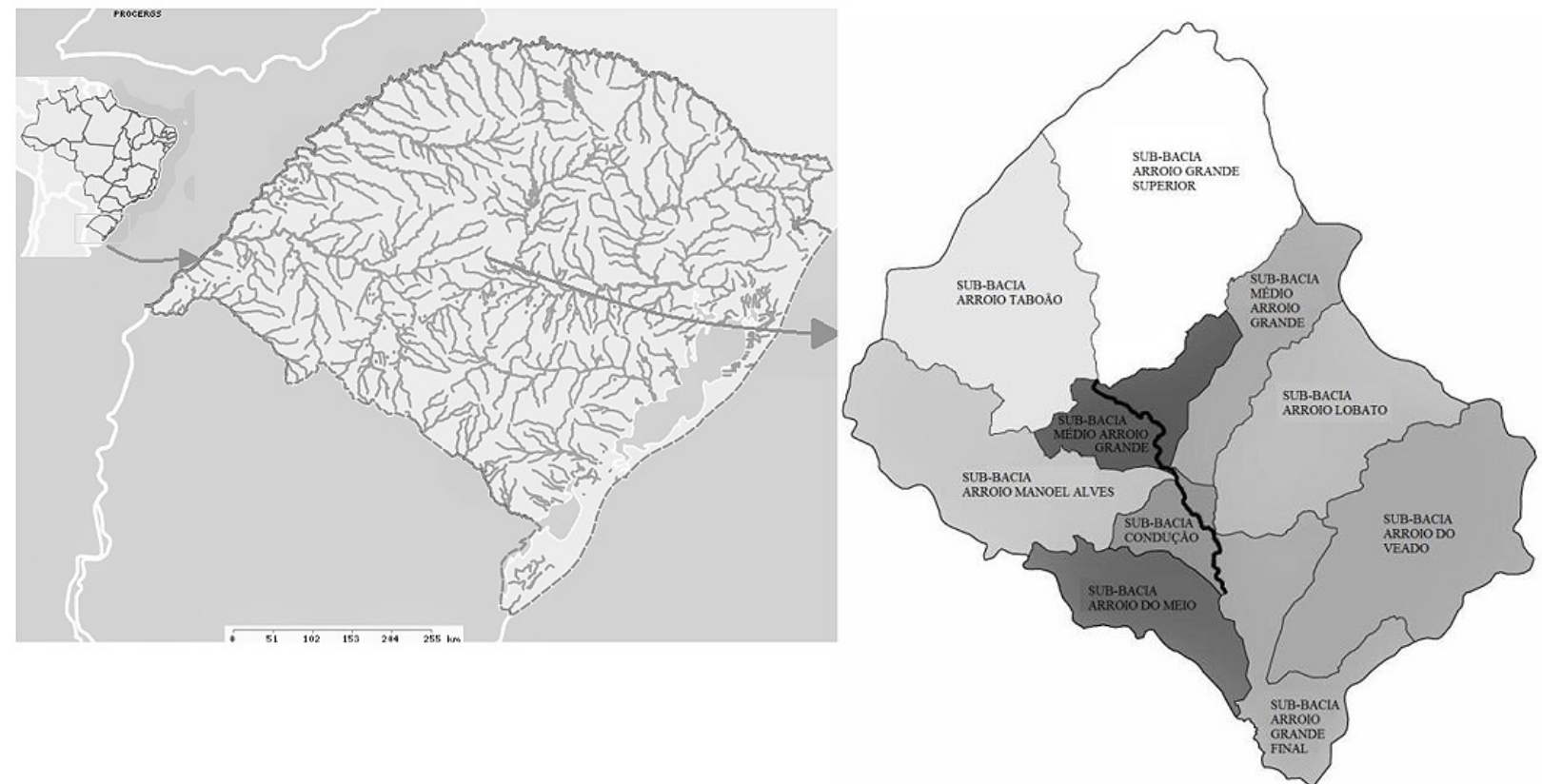

FIGURA 1: Bacia e sub-bacias do Arroio Grande e ao centro o trecho do rio analisado, em Santa Maria RS.

FIGURE 1: Basin and sub-basins of Arroio Grande and in central, the stretch of the river analysed, in Santa Maria - RS.

O leito maior hidrológico (LMH) foi delimitado utilizando-se o modelo hidrológico desenvolvido por Miola (2013). Para tanto, utilizaram-se dados da distribuição das chuvas na região, selecionando-se as chuvas máximas diárias, as quais foram transformadas em vazões máximas diárias, para um tempo de retorno de 1,1 anos. Desta forma, foi possível observar as áreas alagadas para este fluxo anual e transformálas em uma faixa de delimitação, o LMH, e visualizar o início da APP, segundo o ACF. A análise desta definição foi feita por meio da equação 1 .

$$
F P P(A C V)=L M H+A P P
$$

Em que: FPP = Faixa de Proteção Permanente; ACV = Antigo Código Florestal; LMH = Leito Maior Hidrológico; e APP = Área de Preservação Permanente.

Além disso, sabendo-se que a legislação vigente é embasada no LR de um rio, o mesmo foi definido para o trecho em estudo utilizando-se imagens do satélite GeoEye-1, que abastece o aplicativo Google 
Earth $^{\odot}$, datadas de 2011. Essas imagens foram importadas para o software AutoCAD Civil 3D 2010@, no qual, posteriormente, analisou-se o cenário de implantação da APP para o referido curso d'água. Para tanto, utilizou-se a equação 2.

$$
F P P(N C F)=L R+A P P
$$

Em que: FPP = Faixa de Proteção Permanente; NCF = Novo Código Florestal; LR = Leito Regular; e APP = Área de Preservação Permanente.

Para analisar a variação da largura do LR do rio de forma mais detalhada, foram levantadas duas (2) seções transversais do Arroio Grande, no início e no final do trecho de estudo, nas quais se realizou a comparação com as imagens de satélite, utilizando-se uma Estação Total da marca Leica TC407.

Após definir a extensão dos leitos e das suas respectivas APPs, as duas faixas de proteção encontradas, segundo ambas as legislações (ACF e NCF), puderam ser analisadas, observando-se os valores encontrados.

O NCF traz duas metodologias para definição da APP de um curso d'água, sendo a mesma relativa a duas finalidades diferentes, conservação ou recomposição de áreas. Ele utiliza o tamanho da propriedade rural na definição da largura da APP de curso d'água a ser recuperada, mas este estudo não utilizou este parâmetro, visto que não houve identificação dos proprietários das áreas ribeirinhas, e, por consequência, não foi possível ter acesso às matrículas dos imóveis correspondentes. Assim, definiu-se, neste estudo, que não ocorrem pequenas propriedades na bacia do Arroio Grande, e definido esse critério, avaliou-se a diferença de área a ser protegida pelas APPs e não a área que deveria ser recomposta. Segundo normatização do Instituto Nacional de Colonização e Reforma Agrária (INCRA), para propriedades localizadas no município de Santa Maria, 01 (um) módulo fiscal equivale a 22 ha.

\section{Uso do solo dentro das Faixas de Proteção Permanente (FPP)}

Após a delimitação do LR e do LMH e da extensão de cada faixa de APP, foi possível analisar, por meio do mapeamento do uso do solo, a diferença na aplicabilidade das leis (ACF e NCF) quanto à possível adequação e recuperação do passivo ambiental eventualmente existente dentro das propriedades. O uso do solo foi identificado manualmente utilizando imagens do satélite GeoEye-1, utilizando-se o software AutoCAD Civil 3D $2010^{\circ}$. O uso do solo foi classificado em estrada, campo, construção, inaproveitável (áreas de erosão, areia exposta e afloramentos rochosos), lavoura, mato nativo e floresta implantada com espécies exóticas.

\section{Dificuldades na determinação da Área de Preservação Permanente (APP)}

Desta forma, este trabalho avaliou as questões enfrentadas pelos técnicos que deverão instruir os proprietários rurais na adequação das áreas rurais à legislação ambiental, consciente que os órgãos fiscalizadores utilizarão imagens de satélite para fiscalização destas áreas.

Imagens do satélite GeoEye-1 foram utilizadas para a identificação de possíveis padrões de visualização do leito do rio, sendo denominados 04 (quatro) tipos principais: LR bem delimitado; Vegetação encobrindo o LR; Presença de ilhas e praias fluviais; Presença de meandros abandonados.

Através dessa análise, apresentaram-se possíveis alternativas para a solução das dificuldades encontradas no processo de delimitação do LR, bem como alternativas para o aprimoramento do Código Florestal.

\section{RESULTADOS E DISCUSSÃO}

\section{Delimitação da Área de Preservação Permanente (APP) do Arroio Grande}

O LMH e LR definidos, para o trecho em estudo do Arroio Grande, demonstraram que há grande 
diferença entre os mesmos, sendo que a largura do LMH é maior que a largura de toda a FPP definida pelo $\mathrm{NCF}$, e somente a área de LMH soma 252,91 ha, mais que o dobro de toda a área de FPP demarcada pelo NCF. Pode-se observar que ocorre grande diminuição da área a ser preservada com a APP de um curso d'água com as modificações na legislação (NCF).

A utilização do LMH no ACF, e desde que efetivamente implantada a APP, com abandono do uso antrópico e efetiva conservação da área, considerava a variação do regime hidrológico de um sistema hídrico ao longo do ano, que é muito grande em regiões de clima tropical, bem como a variação dos rios intermitentes, de ocorrência comum nas regiões áridas. Com a revisão da lei, estes fatores não são mais considerados, o que acarreta em diversos prejuízos ao ecossistema, visto que o rio perde sua área de extravasamento e, principalmente, ocorre perda de habitat, que se trata da primeira causa de extinção de espécies.

Sabe-se da importância da manutenção de áreas ripárias, e conforme exemplifica Casatti (2010), qualquer diminuição na proteção da dimensão lateral dos cursos d'água pode alterar as entradas de material orgânico e inorgânico, com consequências para todo o sistema aquático. Este fato afeta também os peixes, que são indivíduos ectotérmicos, ou seja, incapazes de regular sua temperatura e dependem, portanto, da floresta ripária para regular a temperatura externa do ambiente e assim, ajustar a sua própria (PUSEY; ARTHINGTON, 2003).

A redução de ambientes ripários protegidos pelo $\mathrm{ACF}$, como os campos úmidos, por exemplo, provavelmente tornará ameaçadas muitas espécies de serpentes que habitam o Cerrado, que hoje não se encontram em perigo de extinção (MARQUES et al., 2010).

Por outro lado, sobre o ACF, os conflitos de delimitação da APP eram comuns, visto que o técnico deveria desenvolver uma metodologia para definição do $\mathrm{LMH}$, ou nível da cheia sazonal, o que requeria análises acuradas e desenvolvimento de um modelo hidrológico para a bacia em estudo, o que raramente era feito. Desta forma, uma margem para erros era aberta dentro da legislação.

Em relação ao NCF, no ponto inicial, o levantamento da seção do Arroio Grande com Estação Total proporcionou visualização correta da largura do LR do rio, visto que pela imagem de satélite a visualização ficava comprometida devido à vegetação existente. No ponto inicial do trecho de rio, foi verificada a largura de 13,51 metros da calha do LR, e no ponto final, foi observada a largura de 21,42 metros da calha do LR (Figura 2). Com estas duas medidas, foi possível definir uma largura média maior que 10 metros e inferior a 50 metros ao longo de todo o trecho, resultando desta forma em uma faixa de APP de 50 metros a partir da calha do LR, segundo o NCF, considerando a finalidade de conservação ambiental dos recursos naturais.

A delimitação do LR por imagens de satélite se mostrou relativamente eficiente, desde que as imagens utilizadas apresentem resolução adequada para esta finalidade e permitam a visualização da calha do rio. Imagens de satélites de alta resolução contribuem positivamente na execução de mapeamentos

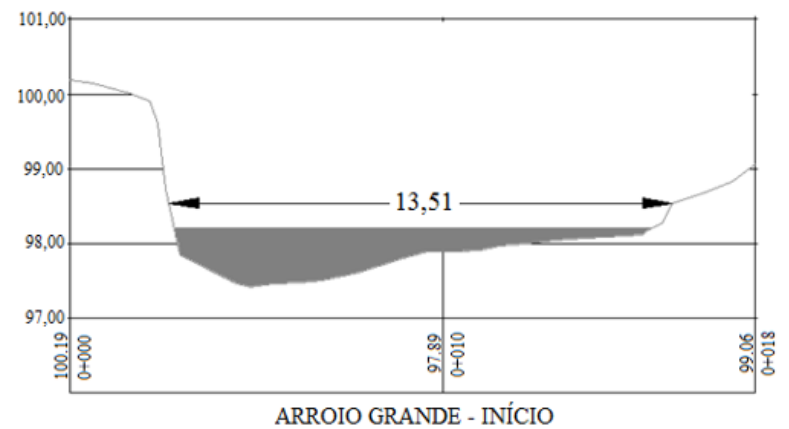

Escala Horizontal - $1: 200$

Escala Vertical - $1: 100$

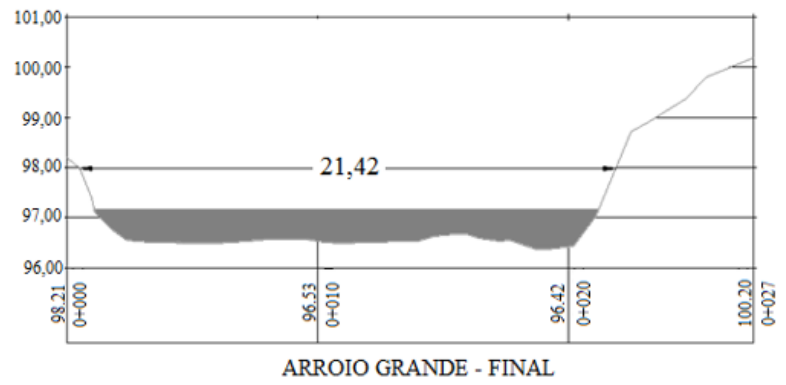

Escala Horizontal - $1: 300$

Escala Vertical - $1: 150$

FIGURA 2: Perfis verticais levantados em Maio de 2013 com Estação Total, no início e no final do trecho em estudo do Arroio Grande.

FIGURE 2: Vertical profiles collected in May 2013 with Total Station, at the beginning and end of the stretch on study of river Arroio Grande. 
topográficos e temáticos, podendo-se citar como exemplo o satélite RapidEye, que forneceu as imagens para utilização no CAR.

A utilização de imagens de satélite é uma ferramenta que pode ser utilizada em estudos dirigidos à dinâmica ambiental, contemplando zonas de rios. Isto pode ser confirmado comparando a diferença entre o LMH e o LR do Arroio Grande (Tabela 1), pois se verificou que o comportamento desta relação é diferente, conforme a morfologia do rio. No início do trecho, no qual o relevo é característico de regiões de altitude, o LR fica bem encaixado e possui largura inferior, em relação ao LMH, que ocupa uma área maior (em hectares), desta forma, com o NCF, estes locais perderam grande área que anteriormente era protegida. No trecho intermediário entre o inicial e o final, neste caso, observou-se a menor diferença entre a área de LR e $\mathrm{LMH}$, sendo que no final do trecho, cujo relevo é de planície, a perda de área protegida voltou a ser maior, visto que a área alagada pelo LMH é grande e ocupa as áreas de várzea existentes.

TABELA 1: Área da Faixa de Proteção Permanente (FPP), conforme o Antigo (ACF) e o Novo Código Florestal (NCF) para o Arroio Grande segundo diferentes legislações.

TABLE 1: Area Range of Permanent Protection (FPP) according to the Old (ACF) and New Forest Code (NCF) for the Arroio Grande under different legislation.

\begin{tabular}{|c|c|c|c|}
\hline Arroio Grande & ACF (ha) & NCF (ha) & Perda de área protegida (\%) \\
\hline Trecho 01 & 75,85 & 3,58 & 95,28 \\
\hline Trecho 02 & 56,86 & 8,37 & 85,28 \\
\hline Trecho 03 & 120,20 & 11,10 & 90,76 \\
\hline APP (50 metros) & 108,67 & 110,40 & - \\
\hline Total & 361,58 & 133,45 & 63,09 \\
\hline
\end{tabular}

Embora as regras para fins de conservação se mantiveram inalteradas após a revisão do Código Florestal, as regras de recomposição se tornaram bastante complexas. Primeiro, porque a recuperação do passivo de APP de curso d'água passou a usar uma regra conhecida como "escadinha", na qual a faixa a ser recuperada depende, além da largura do rio, do tamanho do módulo fiscal, que varia para cada município (SOARES-FILHO, 2013). Este fator dificulta o estudo e a análise da FPP em uma bacia, visto que se necessita do conhecimento fiel do tamanho de cada propriedade (registrado na matrícula do imóvel) situada ao longo do rio, e dependendo ainda do município, a faixa de APP com fins de recuperação será diferente.

Destaca-se a diferenciação apresentada no NCF para áreas que necessitam recomposição. Nestes casos, a largura mínima de APP é menos extensa, estimulando o proprietário a efetuar a recuperação, o que não acontecia pela legislação anterior, na qual as áreas ribeirinhas, conservadas ou não, deveriam ser recuperadas por no mínimo 30 metros de largura, o que na maioria das vezes não era respeitado por parte dos proprietários. $\mathrm{O}$ acesso a um meio ambiente equilibrado e preservado se tornou um direito humano básico, portanto, a normatização dos temas ambientais é tema fundamental para a sociedade (LORENZETTI, 2012).

Considerando a menor faixa de APP citada no NCF, que é a recomposição de 5 metros de faixa ciliar contados a partir da borda da calha do LR, independentemente da largura do curso d'água, para propriedades com até 01 (um) módulo fiscal, para a área em estudo, um total de 2,43 ha de área de faixa ciliar não vegetada, ou seja, ocupada irregularmente por lavouras ou outras atividades, seriam recompostos. Isto enfatiza o ganho ambiental para a sociedade quando a legislação ambiental é efetivamente respeitada.

A demarcação das APPs dos cursos d'água de uma bacia localizada em São Paulo foi realizada por Campos e Matias (2012), utilizando-se cartas topográficas em escala 1:10.000, sendo que não foi possível delimitar a APP dos rios, porque a maioria deles está representada por linhas simples nas cartas, inviabilizando a identificação da largura dos mesmos. Dessa forma, os autores mediram as larguras com auxílio dos satélites do programa Google Earth ${ }^{\odot}$, através de imagens de satélite, metodologia semelhante à utilizada neste estudo. As limitações da análise de ambas as versões do Código Florestal são muitas, como a ausência de um registro cartográfico unificado da malha fundiária nacional, mapas em escala de detalhe 
da rede de drenagem, registro das larguras dos rios e de uma base integrada por todos os remanescentes de vegetação nativa nos seus vários estágios de conservação e regeneração.

Além disso, a recuperação de matas ciliares deve ocorrer no contexto do manejo integrado de microbacias hidrográficas, ressaltando que não se deve restringir apenas à recuperação da mata nas áreas que margeiam os rios, mas sim ao manejo da bacia hidrográfica como um todo (SALEMI et al., 2011).

Ressalta-se, desta forma, a importância da implementação prática do Código Florestal Brasileiro, para que os benefícios obtidos com a eficiência da lei comecem a ser visualizados. Espera-se que ocorra uma potencialização na capacidade de gestão das entidades públicas, assim como a participação da sociedade promovendo a defesa das áreas protegidas, como as APPs. Além disso, a efetiva implantação prática facilita o entendimento da população ribeirinha sobre a demarcação da APP, do início desta a partir da borda do rio (OLIVEIRA, 2011).

Sobre os 50 metros delimitados pela APP, Silva (2003) definiu em seu estudo as larguras ideais para que as funções da mata ciliar sejam cumpridas, indicando que se fosse restabelecida a vegetação ao longo dos 50 metros de APP, a mesma cumpriria algumas de suas principais funções ambientais, como estabilização de taludes, habitat de peixes, remoção de nutrientes e controle de sedimentos do rio.

Apesar da aplicação do Código Florestal ser pouco efetiva desde a sua criação, há uma busca por esclarecimentos por parte dos produtores. Mendes, Neves e Berger (2012) analisaram a visão dos proprietários rurais no município de Otacílio Costa - SC em relação à legislação de $\mathrm{APP}$ e, como resultado, observaram que a maioria deles define que "proteger a APP é importante para conservar as águas, atender à legislação e manter uma reserva de madeira". Este fator mostra certa confusão entre APP e Reserva Legal, já que a floresta em APP não pode ser explorada.

\section{Análise do uso do solo dentro das Faixas de Proteção Permanente (FPPs)}

Considerando uma faixa de 50 metros a partir da borda da calha do LMH, definiu-se a APP do Arroio Grande segundo o ACF (Tabela 2). Salienta-se que a maioria das atividades antrópicas existentes dentro do LMH do Arroio Grande trata-se de lavouras. Desta forma, conclui-se que 804.919,57 kg de arroz são produzidos dentro do leito maior do Arroio Grande, no trecho em estudo.

A delimitação de 50 metros foi definida em razão de uma coerência com a paisagem existente, visto que em alguns pontos a largura do LMH foi de mais de 700 metros, desta forma, uma APP de 500 metros nesta bacia extrapolaria o limite da bacia, além de ser um valor não utilizado para esta região.

Em relação à área de floresta implantada com espécies exóticas, salienta-se que este tipo de atividade é comum nesta região, sendo observada nas visitas a campo que muitos proprietários optam

TABELA 2: Uso do solo dentro da Faixa de Preservação Permanente (FPP) do Arroio Grande segundo o Antigo Código Florestal (ACF). Data das imagens: 21/09/2011.

TABLE 2: Soil use within the Range of Permanent Preservation (FPP) of the Arroio Grande according the Old Forest Code (ACF). Date of the images: 09/21/2011.

\begin{tabular}{lcccc}
\hline \multirow{2}{*}{ Descrição } & \multicolumn{2}{c}{ APP } & \multicolumn{2}{c}{ LMH } \\
\cline { 2 - 5 } & Área (ha) & Área (\%) & Área (ha) & Área (\%) \\
\hline Mata nativa & 22,48 & 20,7 & 79,58 & 31,5 \\
Lavoura & 61,37 & 56,5 & 108,29 & 42,8 \\
Estrada & 1,31 & 1,2 & 2,59 & 1,0 \\
Construção & 1,02 & 0,9 & 1,81 & 0,7 \\
Floresta implantada & 3,29 & 3,0 & 5,46 & 2,2 \\
Campo & 13,59 & 12,5 & 41,48 & 16,4 \\
Água & 0,61 & 0,6 & 0,60 & 0,2 \\
Inaproveitável & 5,02 & 4,6 & 13,11 & 5,2 \\
\hline \multicolumn{1}{c}{ Total } & 108,67 & 100,0 & 252,91 & 100,0 \\
\hline \multicolumn{1}{c}{} & & & & \\
\hline
\end{tabular}


por implantar a silvicultura em locais em que não é possível o cultivo de culturas anuais. Em relação à silvicultura com espécies exóticas, Rosa, Buffon e Kehl (2010) concluíram que o principal impacto causado por esta atividade dentro de áreas de preservação refere-se ao risco de invasões biológicas, juntamente com a destruição de habitat e a exploração humana direta. Por outro lado, este tipo de atividade pode ser uma alternativa para se conectar áreas de vegetação nativa, formando corredores físicos na paisagem.

Abaixo, uso do solo dentro da APP do Arroio Grande segundo o NCF (Tabela 3).

TABELA 3: Uso do solo dentro da Área de Preservação Permanente (APP) do Arroio Grande segundo o Novo Código Florestal (NCF). Data das imagens: 21/09/2011.

TABLE 3: Soil use within the Range of Permanent Preservation (APP) of the Arroio Grande according the New Forest Code (NCF). Date of the images: 09/21/2011.

\begin{tabular}{|c|c|c|}
\hline Descrição & Área (ha) & Área $(\%)$ \\
\hline Mata nativa & 62,52 & 56,6 \\
\hline Lavoura & 21,69 & 19,6 \\
\hline Estrada & 0,94 & 0,9 \\
\hline Construção & 0,69 & 0,6 \\
\hline Floresta Implantada & 2,17 & 2,0 \\
\hline Campo & 14,74 & 13,4 \\
\hline Água & 0,66 & 0,6 \\
\hline Inaproveitável & 6,99 & 6,3 \\
\hline Total & 110,40 & 100,0 \\
\hline
\end{tabular}

De um total de 110,4 ha de APP demarcada pelo NCF, 56,6\% é formado por mata nativa, o que se deve ao fato de a área à montante da bacia ter a paisagem bastante preservada. Este valor é exatamente o mesmo percentual de lavouras encontrado na faixa de APP delimitada pelo ACF, sugerindo que a nova legislação pode ter trazido menos interferência nas atividades antrópicas implantadas ilegalmente na bacia.

Salienta-se a formação de corredores ecológicos com a preservação das áreas de mata nativa na APP do Arroio Grande, com um total de $56,6 \%$ da bacia coberta por vegetação nativa. Na face montante da bacia está a maior porcentagem de vegetação arbórea nativa, principalmente devido ao fato de serem áreas mais declivosas, nas quais as atividades agrícolas se tornam mais onerosas.

Analisando a distribuição espacial das APPs delimitadas para a sub-bacia hidrográfica do rio Camapuã/Brumado, Gonçalves et al. (2012) também perceberam a formação natural de corredores ecológicos, conectando os fragmentos florestais remanescentes na bacia, reafirmando desta forma a eficiência da legislação ambiental, quando aplicada.

Toda paisagem deveria manter a vegetação ripária, dados os seus benefícios para a conservação das espécies. Segundo Metzger (2010), a largura destes corredores vegetados interfere na qualidade do habitat protegido, regulando desta forma o total de área impactado por efeitos de perturbação de borda e modificações microclimáticas. Entre os efeitos de borda observados, o autor cita o aumento da luminosidade e do ressecamento do ar e do solo, maior incidência de espécies invasoras e perturbações ocasionais, como rajadas de vento e queimadas.

A fonte de água mais utilizada na irrigação de lavouras de arroz na bacia do Arroio Grande é o próprio rio (SANTOS, 2005). O autor concluiu que a aplicação da legislação ambiental poderia reduzir a renda do produtor de arroz na bacia do Arroio Grande, sendo essa redução proporcional à redução da área plantada.

Este fator pôde ser comprovado na análise do APP definida, visto que há uma área de 21,69 ha de lavouras dentro da APP de 50 metros do rio, segundo o NCF. Como citado anteriormente, o IRGA informa que na última safra a produtividade média do arroz foi de 7.433 quilos por hectare. Desta forma, haveria uma redução de $161.221,77 \mathrm{~kg}$ de arroz produzido na área em estudo, e com o fardo de $60 \mathrm{~kg}$ do arroz cotado a uma média de $\$ 34,00$, isto representa um total de $\mathrm{R} \$ 91.359,00$ na economia da região. De 
qualquer forma, estes valores seriam obtidos em áreas irregulares e não podem ser contabilizados, dada a importância da proteção da bacia hidrográfica, visando a sua sustentabilidade.

O uso e ocupação do solo nas zonas ripárias de seis bacias hidrográficas de pequeno e grande porte situadas na parte superior da bacia do rio Itajaí - SC foi estudada por Pinheiro et al. (2011), os autores observaram que as APPs ao longo dos cursos d'água eram intensivamente usadas pela agricultura, apresentando uma cobertura florestal deficitária, necessitando de ações urgentes de recuperação.

Os desmoronamentos de taludes têm origens distintas, dependentes de diversos fatores como condição do solo, uso da superfície (retirada de vegetação, por exemplo) e composição das forças hidrodinâmicas (direção e velocidade) (BERNÁL, 2013). Na foz do arroio Manoel Alves, junto ao Arroio Grande, é possível verificar a situação crítica dos taludes do rio (Figura 3). Observa-se que não há vegetação ciliar e nenhum tipo de proteção ao talude.

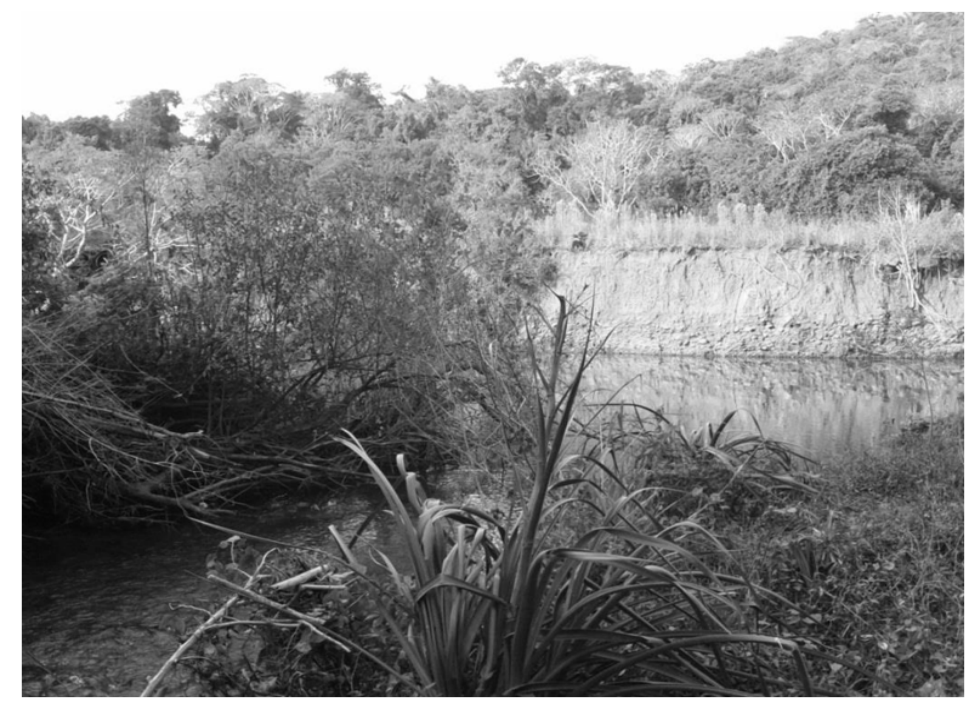

FIGURA 3: Foz do arroio Manoel Alves no Arroio Grande. Data: 17/05/13.

FIGURE 3: Mouth of the stream Manoel Alves in the Arroio Grande. Date: 05/17/13.

Em um estudo similar, Campos e Matias (2012) verificaram que ações isoladas do poder público na recuperação de algumas APPs são insuficientes para reverter um quadro geral de degradação. Os autores sugerem campanhas de conscientização da população sobre o que são as APPs e sua função para conservação do meio ambiente. Estes autores evidenciam que, de posse do mapeamento das APPs de um município, o poder público deve tomar uma posição ativa de fiscalização, impedindo desta forma que novas áreas sejam degradadas e visando à recuperação das áreas indevidamente ocupadas. Salemi et al. (2011) salientam que se trata de um cenário bastante comum em regiões agrícolas do Brasil observar corpos d'água com sinais de degradação como assoreamento, desbarrancamento de margens e redução de suas vazões.

A estabilidade das margens de um curso d'água está condicionada às características geomorfológicas do terreno marginal, à ocupação destas terras, ao regime hídrico e ao processo hidrodinâmico da sua calha, sendo que a ação antrópica tem grande influência no processo de desestabilização destas margens, uma vez que as atividades humanas tendem a ser impactantes negativas (BERNÁL, 2013).

\section{Dificuldades da delimitação do Leito Regular (LR) do Arroio Grande}

A delimitação da APP por imagens de satélite é facilmente interpretada quando o LR está visível, isto ocorre porque o rio aparece encaixado na sua calha, mesmo estando em um nível mais alto, por exemplo. Por outro lado, quando o leito fica encoberto pela vegetação, é usual utilizar os dados observados antes e depois deste trecho, isto quando não há possibilidade de vistoria à área.

Em diversos pontos do Arroio Grande verifica-se a presença de ilhas fluviais, sendo que as mesmas fazem parte do LR do rio. 
Os meandros abandonados não fazem parte do LR do rio que é passível de APP (Figura 4). Ao longo do Arroio Grande, são encontrados alguns pontos com essa conformação, na parte jusante do rio, na qual a paisagem de várzea é preponderante. Sem sua proteção, pode-se perder importante habitat ao não considerar o meandro, especialmente se ainda for área úmida (Figura 4).

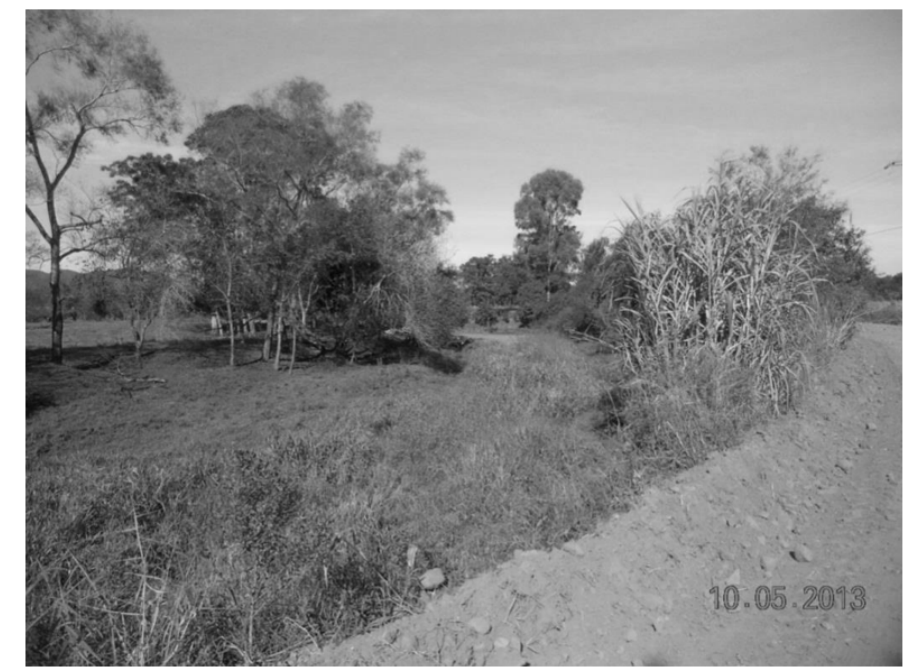

FIGURA 4: Meandro abandonado do Arroio Grande. Fonte: Arquivo pessoal. Data: 10/05/13.

FIGURE 4: Abandoned meander of the river Arroio Grande. Source: Personal archive. Date: 05/10/13.

A migração dos canais meandrantes ocorre pelo processo contínuo de escavação na margem côncava e deposição na margem convexa (ZANCOPÉ; PEREZ FILHO; CARPI JUNIOR, 2009). Rios maduros, que percorrem planícies e que já atingiram o seu nível de base apresentam um curso sinuoso, com presença de meandros, e que é comum a presença de lagos ao longo destes rios (ESTEVES, 1998). Segundo o autor, estes lagos são formados através do isolamento de meandros por processos de erosão e sedimentação das margens. Este isolamento acaba então mudando o curso do rio, deixando parte do leito isolado e, desta forma, abandonado pelas águas do rio.

O NCF não considera a proteção de meandros abandonados. A maioria destes meandros que costuma formar lagos naturais, que passam a ser protegidos pelo NCF em seu Item II, que cita APP para "Áreas no entorno dos lagos e lagoas naturais", desde que possuam tamanho superior a 1 ha, como diz a Lei n. 12.727 (BRASIL, 2012) dispensa o estabelecimento das faixas de APP no entorno das acumulações naturais ou artificiais de água com superfície inferior a 1 (um) hectare, vedada nova supressão de vegetação nativa.

Ainda, os meandros abandonados podem adquirir características de banhados. Banhados são áreas alagadas permanente ou temporariamente, que, segundo o Código Estadual do Meio Ambiente do RS (Lei n. 11.520/2000) (RIO GRANDE DO SUL, 2000), são definidos como "extensões de terras normalmente saturadas de água onde se desenvolvem fauna e flora típicas". Segundo o NCF, Art. 6 item IX, deve-se "proteger áreas úmidas, especialmente as de importância internacional" (incluído pela Lei $n^{\circ} 12.727$, de 2012), sendo que esta mesma define como áreas úmidas "pantanais e superfícies terrestres cobertas de forma periódica pela água, cobertas originalmente por florestas ou outras formas de vegetação adaptadas à inundação".

Através da análise da discussão dos resultados, observou-se que a legislação a ser aplicada com o NCF carece de muitos estudos técnicos para que sua efetividade seja confirmada, bem como os benefícios propostos. Ferraz (2012) comenta que muitos cientistas de instituições de pesquisa não são ativamente envolvidos nos estudos de licenciamento, e desta forma não são consultados na formulação das orientações técnicas que são utilizadas nas legislações, sabendo que os mesmos poderiam contribuir com seu conhecimento em processos públicos de decisão. 


\section{CONCLUSÕES}

Ao longo do trecho analisado do Arroio Grande, segundo a Lei $n^{\circ}$ 12.727/2012 (NCF), deve-se manter 50 metros de APP a partir da calha do leito regular do Arroio Grande para que as finalidades de preservação sejam alcançadas, como formação de corredores ecológicos. Sugere-se considerar como LR a calha delimitada do rio, incluídas as praias e ilhas fluviais.

O banco de imagens oferecido pelo Governo Federal através do CAR é uma informação importante de apoio aos órgãos fiscalizadores, podendo auxiliar no alcance das metas internacionais de manutenção de vegetação nativa. Mesmo assim, as imagens de satélite não devem ser a única alternativa para determinação da APP de cursos d'água, visto que em muitos locais a vegetação encobre o leito do rio, devendo ser realizadas visitas in loco para melhor visualização do terreno.

Sobre as APPs do Arroio Grande, destaca-se que 22,2\% das áreas que deveriam estar protegidas de acordo com o NCF estão em uso inadequado à sua finalidade, colocando estas propriedades na ilegalidade perante a legislação ambiental e comprometendo o equilíbrio da bacia. Pelo ACF, a área em uso irregular chegava a $50,1 \%$.

A modificação do início da faixa de APP do LMH para o LR trouxe grande perda de área protegida. Além disso, a largura das faixas de APP também pode ser manuseada conforme o tamanho da propriedade, o que causa instabilidade e variação da faixa protegida, podendo acarretar em perda da sua funcionalidade.

Apesar disso, a alteração da legislação tornou a sua aplicação mais objetiva, diferentemente do ACF, que era baseado na delimitação do LMH, o que, muitas vezes, dificultava sua aplicação. O NCF também permite aos proprietários rurais a adequação das áreas degradadas em uma faixa menor de preservação, excluindo a justificativa de que o ACF não era respeitado devido à área de proteção ser extensa e invariável.

A aplicação da legislação ambiental brasileira ainda é tema de muitas discussões e abre um extenso campo de estudo. Para que todos os questionamentos sejam respondidos, recomenda-se aos cientistas maior empenho na realização de pesquisas referentes a este tema, como por exemplo, a análise da redução da área de FPP, verificando se este fator causa impactos significativos no sistema ribeirinho, como por exemplo, em relação à perda de habitat da fauna existente nestes locais.

Outro tema que pode ser analisado é a verificação do efetivo ganho em áreas de produção com a modificação das regras de APP, e se esta modificação compensa a perda ambiental existente. Ainda, a aplicação da legislação ambiental em bacias rurais, com informação das matrículas das propriedades, para verificação da extensão exigida nas APPs de rios e da existência, ou não, de uma faixa de proteção irregular nestes locais.

\section{REFERÊNCIAS}

BERNÁL, F. H. Determinação de parâmetros para avaliação da estabilidade de taludes marginais em leito de rio. 2013. 123 f. Tese (Doutorado em Engenharia Florestal) - Universidade Federal de Santa Maria, Santa Maria, 2013.

BRASIL. Lei Federal n. 4.771 de 15 de Setembro de 1965. Código Florestal Brasileiro. Disponível em: $<$ http://www.planalto.gov.br/ccivil_03/leis/14771.htm>. Acesso em: 22 mar. 2013.

BRASIL. Lei Federal n. 12.651 de 25 de maio de 2012. Código Florestal Brasileiro. Disponível em: $<$ http://www.in.gov.br/mp_leis/leis_texto.asp?ld=LEI\%209887>. Acesso em: 22 dez. 2013.

BRASIL. Lei Federal n. 12.727 de 17 de outubro de 2012. Código Florestal Brasileiro. Disponível em: $<$ http://www.planalto.gov.br/ccivil_03/_Ato2011-2014/2012/Lei/L12651.htm>. Acesso em: 21 mar. 2013. CAMPOS, F. F.; MATIAS, L. F. Mapeamento das Áreas de Preservação Permanente (APP's) e sua situação de uso e ocupação no município de Paulínia (SP). Geociências, Rio Claro, v. 31, n. 2, p. 309-319, 2012.

CASATTI, L. Alterações no Código Florestal Brasileiro: impactos potenciais sobre a ictiofauna. Biota Neotropica, Campinas, v. 10, n. 4, p. 31-34, 2010.

COELHO, R. C. T. P.; BUFFON, I.; GUERRA, T. Influência do uso e ocupação do solo na qualidade da água: um método para avaliar a importância da zona ripária. Revista Ambiente e Água, Taubaté, v. 6, p. 104-117, 2011.

CRIADO, R. C. Levantamento das Áreas de Preservação Permanente no canal principal do alto curso do 
Rio Paranapanema - SP. Geografia em atos, Presidente Prudente, v. 2, n. 8, 2008.

ESTEVES, F. A. Fundamentos de limnologia. 2. ed. Rio de Janeiro: [s. n.], 1998. 602 p.

FERRAZ, G. Twelve Guidelines for Biological Sampling in Environmental Licensing Studies. Natureza \& Conservação, Rio de Janeiro, v. 10, n. 1, p. 20-26, jul. 2012.

GONÇALVES, A. B. et al. Mapeamento das Áreas de Preservação Permanente e identificação dos conflitos de uso da terra na sub-bacia hidrográfica do Rio Camapuã/brumado. Revista Árvore, Viçosa, MG, v. 36, n. 4, p. 759-766, 2012.

LORENZETTI, J. V. Alteração do Código Florestal Brasileiro: a dinâmica da esfera pública no Estado do Rio Grande do Sul. 2012. 114 f. Dissertação (Mestrado em Administração) - Universidade Federal do Rio Grande do Sul, Porto Alegre, 2012.

MARQUES, O. A. V. et al. Impactos potenciais das mudanças propostas no Código Florestal Brasileiro sobre os répteis brasileiros. Biota Neotropica, Campinas, v. 10, n. 4, p. 39-42, 2010.

MENDES, C. J.; NEVES, C. U.; BERGER, R. Áreas de Preservação Permanente e Reserva Legal: percepção dos proprietários rurais do município de Otacílio Costa, SC. Floresta, Curitiba, v. 42, n. 4, p. 671-682, 2012. METZGER, J. P. O Código Florestal tem Base Científica? Fórum - Natureza \& Conservação, Curitiba, v. 8, n. 1, p. 92-99, 2010.

MIOLA, A. C. Planejamento para comunidades rurais em situações de enchentes. 2013. 225 f. Tese (Doutorado em Engenharia Agrícola) - Universidade Federal de Santa Maria, Santa Maria, 2013.

OLIVEIRA, R. C. N. Caracterização das áreas de domínio da união e da faixa marginal de proteção em rios federais apoiado por modelação matemática: estudo de caso: Médio Rio Paraíba do Sul. 2011. 226 f. Dissertação (Mestrado Profissional em Engenharia Ambiental) - Universidade Federal do Rio de Janeiro, Rio de Janeiro, 2011.

PINHEIRO, A. et al. Uso do solo na zona ripária de bacias agrícolas de pequeno a médio porte. Revista Árvore, Viçosa, MG, v. 35, n. 6, p. 1245-1251, 2011.

PUSEY, B. J.; ARTHINGTON, A. H. Importance of the riparian zone to the conservation and management of freshwater fish: a review. Marine \& Freshwater Research, Australia, v. 54, p. 1-16. 2003.

RIO GRANDE DO SUL. Lei Estadual n. 11.520 de 03 de Agosto de 2000. Código Estadual de Meio Ambiente. Disponível em: <http://www.al.rs.gov.br/legiscomp/arquivo.asp?idNorma=11\&tipo=pdf > Acesso em: 17 nov. 2015.

ROSA, E. M.; BUFFON, I.; KEHL, L. G. H. Avaliação da qualidade de áreas de preservação permanente ripárias em São Francisco de Paula - RS: uma abordagem metodológica. Revista de Ciências Ambientais, Canoas, v. 4, n. 2, p. 17-30, 2010.

SALEMI, L. F. et al. Aspectos hidrológicos da recuperação florestal de Áreas de Preservação Permanente ao longo dos corpos de água. Revista do Instituto Florestal, São Paulo, v. 23, n. 1, p. 69-80, 2011.

SANTOS, A. H. O. Impacto da aplicação da legislação ambiental na produção orizícola da bacia hidrográfica do Arroio Grande - Santa Maria - RS. 2005. 126 f. Tese (Doutorado em Engenharia Agrícola) -Universidade Federal de Santa Maria, Santa Maria, 2005.

SOARES-FILHO, B. S. Impacto da revisão do Código Florestal: como viabilizar o grande desafio adiante? Brasília: Secretaria de Assuntos Estratégicos, 2013. 28 p.

SILVA, R. V. Estimativa de largura de faixa vegetativa para zona ripária. In: SEMINÁRIO DE HIDROLOGIA FLORESTAL: ZONAS RIPÁRIAS, 1., 2003. Anais... Florianópolis: UFSC/PPGEA, 2003. p. 74-87.

TEREZAN, E. L. Delimitação do Leito Maior do Baixo Rio Ivai e Estabelecimento de sua sazonalidade. 2005. 88 f. Dissertação (Mestrado em Geografia) - Universidade Estadual de Maringá, Maringá, 2005.

ZANCOPÉ, M. H. C.; PEREZ FILHO, A.; CARPI JUNIOR, S. Anomalias no perfil longitudinal e migração dos meandros do Rio Mogi Guaçu. Revista Brasileira de Geomorfologia, Uberlândia, São Paulo, v. 10, n. 1, 2009. 